\title{
O Grupo e a revista científica Comunicar: 15 anos pela e para a educomunicação na Espanha
}

\section{J. Ignacio Aguaded Gómez}

Doutor em Psicopedagogia; vice-reitor de Tecnologias, Inovação e Qualidade da Universidade de Huelva (Espanha); diretor do Grupo Comunicar (Espanha).

E-mail: director@grupocomunicar.com

Resumo: Em 1994, surgia em São Paulo (Brasil) a revista Comunicação \& Educação, com um primeiro número dedicado à leitura crítica da comunicação. Exatamente um ano antes havia nascido na Espanha (em Andaluzia) a revista Comunicar, voltada, também, à educação em e para os meios de comunicação. Estas duas publicações irmãs têm tido, a partir daí, vidas paralelas em dois contextos distintos, mas partilhando a preocupação pela importância que a comunicação possui em nossas sociedades e pela necessidade de oferecer respostas no âmbito educacional com base em associações civis, universidades e fóruns de reflexão. Nestas páginas descreve-se a história do Grupo que edita a revista espanhola e algumas ações desenvolvidas nos últimos anos por esta associação de profissionais da educação e da comunicação, no âmbito de formação, investigação e edição de materiais.

Palavras-chave: Educação em/para os meios de comunicação, revista, associação de professores, alfabetização, leitura crítica.
Abstract: In 1994 it was launched in São Paulo (Brazil) the journal Comunicação \& Educação, with a first issue dedicated to the critical reading of communication. Exactly one year before, in Spain (Andalusia), the journal Comunicar, also dedicated to education in and for media, had been created. Both brother publications have had, since then, parallel lives in distinct contexts, but sharing concern about the importance of communication in our societies and the need of offering answers, in the Education field, by civilian associations, universities and forums of reflexion. In the following pages, it is described the history of the Group that publishes the Spanish journal and some of the actions developed along last years in the areas of formation, investigation and publication of materials by this association of education and communication professionals.

Keywords: Education in/for media, journal, teachers association, literacy, critical reading.

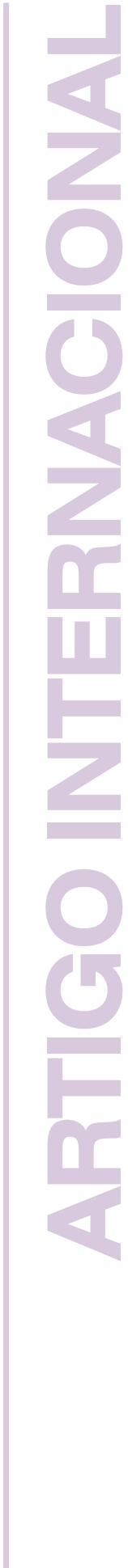

Recebido: 02.09.2008

Aprovado: 08.09.2008 
A irrupção dos meios de comunicação, com o advento, sobretudo, do cinema, posteriormente do rádio e, de forma excepcional, da televisão esta acelerada ainda mais por sua expansão através das redes e da transmissão a cabo -, foi a consagração da revolução midiática. Os meios de comunicação, em seu conjunto, são o pilar básico da sociedade de nossos dias. Eles homogeneízam comportamentos, transmitem novidades, servem como sistemas de equilíbrio e de regulação social e são também o principal cenário de muitos dos conflitos, mas, sobretudo, são o principal veículo de funcionamento da engrenagem mercantilista e de consumo.

Sem dúvida, a informação é o recurso básico da sociedade em que vivemos, definindo de maneira característica as profundas transformações de nossa cultura e dos modos de produção. Toda essa revolução da informação não pode ser compreendida se não for vinculada inexoravelmente ao desenvolvimento tecnológico, inicialmente dos meios de comunicação de massa (cinema, rádio, televisão...), e, nas últimas décadas, ao protagonismo das novas tecnologias da comunicação telemática.

Estamos diante de uma nova era de processamento da comunicação, de conhecimento e de produção de saber, que teve sua base na revolução tecnológica da informática e da telemática e que, por sua vez, foi conectando-se a todos os circuitos tradicionais da comunicação para ir tornando-se cada vez mais globalizada, através da digitalização dos canais e o desenvolvimento da interatividade. Entretanto, o protagonismo crescente da sociedade da informação não deve fazer-nos incorrer em um otimismo universal do poder salvador da comunicação interativa e digitalizada.

A sociedade audiovisual é definida como um universo no qual os meios de comunicação, com suas novas linguagens, constroem de forma vertiginosa e distinta a realidade. Os meios de comunicação e as tecnologias deixaram de ser meras ferramentas preparadas para servir quem as utiliza para tornarem-se parte do sistema cultural que as acolhe. Assim, Sancho afirma que a questão não é que as máquinas tenham assumido o comando, e sim que ao decidir utilizá-las, realizamos muitas escolhas culturais implícitas. A tecnologia não é um simples meio, já que se transformou em um ambiente e uma forma de vida: nisso consiste o seu impacto substantivo ${ }^{1}$.

A partir dos anos 1980, a influência da comunicação e da informação

1. SANCHO, J. La tecnología, un modo de transformar el mundo cargado de ambivalencias (A tecnologia, um modo de transformar o mundo cheio de ambivalências) 1994. In: SAN MARTÍN A. La escuela de las tecnologias (A escola das tecnologias). Valencia: Universidad de Valencia, 1995. no âmbito da atividade econômica, a gestão política, o consumo, o lazer e, em suma, em todas as esferas da vida, altera a ordem dos valores sociais e o estilo de vida das coletividades. A construção de uma sociedade mais democrática - em que cada vez são mais complexas, múltiplas e profundas as interações produzidas entre os cidadãos e o universo dos meios de comunicação - requer um maior processo de análise e interpretação, tanto no âmbito da pesquisa e da educação como no dos pesquisadores das ciências da informação, preocupados não tanto com os meios propriamente ditos, mas com as relações e interações que estes têm com seus espectadores. 
Faz-se necessário, assim, que os indivíduos participem de forma mais ativa em sua interação com os meios de comunicação, dada a crescente influência destes na sociedade atual, para superar o mero papel de receptivos que até agora lhes foi relegado. Neste sentido, é prioritário o conhecimento não só dos meios como fato comunicativo, mas, especialmente, do processo da recepção comunicativa. Nos termos de Orozco, da "perspectiva do público" ${ }^{2}$, de forma que seja analisado como são produzidas as relações dos indivíduos com os meios de comunicação e quais as práticas comunicativas dentro do complexo mundo de interações que estes provocam, sempre com a finalidade de desenvolver as estratégias precisas para melhorar as relações e adquirir as necessárias competências para a apropriação crítica e criativa dos mesmos.

Esse imprescindível e insubstituível esforço interpretativo de conhecer o papel do público no contexto das sociedades contemporâneas ${ }^{3}$ tem como finalidade essencial não tanto prever ou determinar objetivamente o complexo processo de recepção das mídias. Pretende, como indica Orozco, "conseguir compreender o público"4 como um meio necessário para sua transformação e, consequentemente, entender os sistemas de comunicação atuais e, assim, os próprios modelos democráticos das sociedades contemporâneas.

\section{A EDUCAÇÃO E A COMUNICAÇÃO NA ANDALUZIA E NA ESPANHA: O GRUPO COMUNICAR ${ }^{5}$}

A utilização dos meios de comunicação em sala de aula de forma generalizada começa a ocorrer na Espanha na década de 1980, período no qual a educação recebe um forte incentivo do Estado e das Comunidades Autônomas - como a Andaluzia -, que dão início à fase de descentralização da educação, adquirindo cada vez mais competências no âmbito educacional. Assim, no ano de 1986, celebra-se em Benalmádena (Málaga) o 1 Congresso Andaluz de Imprensa e Educação. Nele se reuniram algumas centenas de professores idealistas e sonhadores, e grupos inovadores que consideravam que os meios de comunicação eram instrumentos privilegiados para o desenvolvimento de uma educação comprometida com as demandas de uma nova sociedade. A bandeira a favor do uso da imprensa na escola, apoiada nas múltiplas iniciativas das instituições de educação primárias e secundárias, é retomada por um grupo de professores e jornalistas da província de Huelva. Num jornal local começam a realizar encontros, jornadas, congressos, inicialmente local e progressivamente de caráter regional e nacional. Já em 1987, é criado o Seminário Imprensa Escola, dentro do Centro de Professores de Huelva. Formalmente, em 1988 iria se transformar em associação legalmente constituída, o Grupo Pedagógico Andaluz de Imprensa e Educação. Em 1990, o Coletivo, até aquele momento formado em sua maioria por professores de Huelva, começa a se abrir a docentes de
2. OROZCO, G. Televisión y audiencias. Un enfoque cualitativo (Televisão e público. Um enfoque qualitativo). Madrid: La Torre, 1996.

3. CEBRIÁN HERREROS, $M$. Información audiovisual. Concepto, técnica, expresión y aplicaciones. (Informação audiovisual. Conceito, técnica, expressão e aplicações). Madrid: Síntesis, 1995; SALOMON, G. Investing effort in television viewing (Investindo esforços na programação televisiva). In: MURRAY, J. y SALOMON, G. (Eds.). The future of children television (O futuro da televisão infantil). Nebraska: The Boys Town Center, 1984. p. 59-64.

4. OROZCO, G. Televisión y audiencias, cit.

5. Disponível em: <http:// www.grupocomunicar. com>. 
comunicação \& educação • Ano XIV • Número 1 • jan/abr 2009

toda a Comunidade Autônoma e a jornalistas dos mais distintos veículos, celebrando-se então o 2o Congresso Andaluz de Imprensa e Educação, que representa a consolidação regional do Grupo com a presença de profissionais da educação e da comunicação de toda a Andaluzia.

A partir dos primeiros anos da década de 1990, passam a ser desenvolvidos planos e projetos, cada vez mais dinâmicos, em colaboração com o Conselho de Educação. Contou também com a participação das prefeituras, assembleias, centros de professores, bancos e instituições privadas, que permitem empreender diversas atividades de formação e de sensibilização da comunidade da educação. Assim, dirigidos a todos os alunos andaluzes dos mais de cinco mil centros existentes em nossa comunidade, foram organizadas atividades como os concursos Jovens Jornalistas, para incentivar o uso da imprensa escolar, e realizadas exposições de jornalismo escolar. Para os pais são preparadas oficinas e conferências, a fim de motivá-los a ensinar os filhos a usar os meios de comunicação. Especialmente no âmbito dos docentes, entretanto, é que serão concentradas as principais atividades do Grupo: jornadas como o seminário Professores Dinamizadores da Imprensa, congressos, simpósios, encontros, além de concursos como Salas de aula sem muros.

Em 1992, o Grupo alcança uma ampla implantação regional com representação de todas as províncias. Depois da assinatura de um convênio com a Secretaria de Educação da Andaluzia, abriram-se diversas possibilidades de ação para o desenvolvimento de atividades. A partir desse momento desenvolveram-se duas linhas de atuação: uma geral, de caráter nacional, com o desenvolvimento de projetos para professores já sensibilizados e formados na temática do uso dos meios de comunicação. É o caso, por exemplo, do Simpósio Andaluz ensinar e aprender com a imprensa, rádio e televisão (1992), ou ainda o Congresso Nacional, ocorrido em 1994, em Sevilha, na Isla de la Cartuja, com a presença de mais de 400 especialistas, sob o título Como ensinar e aprender na atualidade com os meios de comunicação? Quase uma década depois, e nesta mesma linha, em 2003, ocorreu um congresso internacional, patrocinado pela Unesco, Unicef e outros organismos internacionais, sob o título Luzes no labirinto audiovisual. Reuniu mais de 700 pesquisadores de 19 países, especialmente latino-americanos, com uma produção científica de 350 comunicações publicadas. Também em 2005, aconteceu outro importante Congresso Latino-Americano, intitulado A televisão que queremos. Por uma televisão de qualidade. Finalmente, em 2007, realizou-se o Fórum Internacional RTVE, em Madri, com a televisão pública como coorganizadora, dedicado a Educar o olhar. Propostas para ensinar a ver televisão.

A outra linha de atuação, de caráter provincial, privilegiou atividades formadoras orientadas essencialmente à sensibilização e iniciação para o uso dos meios de comunicação, com uma vertente prática e uma metodologia própria de oficinas e jornadas. Essa linha, que teve especial relevância no 
final da década de 1990, permitiu a centenas de professores realizar um primeiro contato com a exploração didática dos meios de comunicação. $\mathrm{O}$ uso de todos os meios - imprensa escrita, rádio, televisão, cinema, publicidade, HQs, valores e meios - foi o núcleo temático destes encontros formadores. A cada ano, eram aprofundados alguns dos meios. Foram sempre realizados em colaboração com diferentes instituições e a administração educativa para o desenvolvimento conjunto dos planos formadores dirigidos aos docentes da comunidade.

O Grupo Comunicar desenvolve ainda planos de pesquisa e análise das necessidades dos profissionais da educação e comunicação andaluzes no uso dos meios de comunicação, concretamente em colaboração com todas as universidades andaluzas (num total de dez). O objetivo é conhecer os níveis de exploração e os tipos de necessidades de formação e de recursos audiovisuais e televisivos, demandadas pelos docentes andaluzes.

$O$ plano de atuação de maior abrangência, junto às atividades de formação, é a linha de publicações. Desde 1989, vem permitindo o desenvolvimento de um amplo conjunto de coleções e materiais curriculares em um âmbito temático de implantação até então escasso nas editoras privadas. Destaquem-se, especialmente, as experiências, propostas, reflexões e pesquisas realizadas por docentes em suas aulas. Nesse sentido, o Grupo Comunicar descobriu a necessidade de fomentar entre jornalistas e professores a reflexão e o desenvolvimento de plataformas que possibilitaram a divulgação de inovações desenvolvidas em sala de aula, ou nos meios de fácil aplicação em outros contextos. Atualmente, o Grupo conta com várias coleções abertas e mais de sessenta títulos publicados como editora.

Os Murais Imprensa Escola são jornais-murais (em formato de cartaz) que pretendem fundamentalmente incentivar e motivar a comunidade educacional quanto à necessidade de um uso plural e crítico dos meios de comunicação nos centros de ensino. É uma publicação simples de divulgação científica. Desejam alcançar a necessária sensibilização, mediante abordagens simples, práticas e de fácil adaptação às salas de aula, para introduzir os alunos às novas linguagens que os meios de comunicação colocam em suas mãos. $\mathrm{O}$ intento é de que possam descobri-las, interpretá-las, decodificá-las e usá-las criativamente para o desenvolvimento pessoal e a inserção social. Os Murais são projetados especialmente para jovens estudantes de 12 a 18 anos, e para os alunos dos últimos anos da escola primária, bem como para a educação de adultos. Cada Mural é acompanhado da correspondente ficha didática. Nela são oferecidas sugestões e dicas sobre o processo metodológico que os docentes podem empregar para alcançar ótimos resultados com os Murais, do ponto de vista didático. Estes materiais são, portanto, um recurso de expansão e sensibilização da comunidade educacional, dado que o objetivo do Grupo é enviá-los gratuitamente a todos os centros de educação para que o uso do jornal, do rádio, da televisão e de outros meios de comunicação seja uma realidade nas escolas. Quer, com isso, que estas possam ser inicia- 
6. Disponível em: <http:// www.revistacomunicar. com>.

7. AGUADED, J. I. C\&E, nuevas expectativas en América y Europa ( $C \& E$ novas expectativas $n$ América e na Europa). Comunicar, 30; 7-8. 2008.

8. Ver: SOARES, Ismar Quando o educador do ano é um educomunicador: o papel da USP na legitimação do conceito. Comunicação \& Educação. São Paulo: CCA-ECA-USP/Paulinas, ano XIII, n. 3, set./dez. 2008; BACCEGA，Maria Aparecida. Dez anos a serviço da construção do campo comunicação/ educação. Comunicação \& Educação. São Paulo: CCA-ECA-USP/Paulinas, ano $X$, n. 3, set./dez. 2005 . comunicação \& educação • Ano XIV • Número 1 • jan/abr 2009

das no tratamento didático plural e inovador dos meios de comunicação, a fim de ensinar os alunos a serem cidadãos responsáveis e livres, a partir de uma educação mais crítica, mais criativa e mais lúdica.

Entre as coleções do Grupo, destacam-se especialmente Aula de Comunica$\varsigma \tilde{a} o$, com seis propostas práticas para trabalhar os meios de comunicação em sala de aula:

- Comunicação audiovisual em uma escola renovada.

- A imprensa na educação primária.

- O jornal na educação de adultos.

- Jogar com a imagem. Imaginar jogos.

- O universo de papel.

- O jornal nas aulas.

Outras coleções interessantes do Grupo são:

- Guias Curriculares (5 títulos).

- Aula Mídia (seis títulos).

- Educação e Mídia (três títulos).

A Comunicação Humana (um título), assim como as edições digitais que reúnem diferentes congressos e atividades, além das edições digitais da revista (seis títulos), podem ser consultadas em <http://www.grupocomunicar.com $>$.

O Grupo Comunicar está consciente e convencido de que é cada vez mais necessária a formação de professores e professoras neste âmbito educacional da Educação nos Meios de Comunicação, pelas próprias exigências sociais e demandas do sistema escolar. O surgimento de diversas matérias optativas sobre os meios de comunicação, tanto no ensino fundamental como no ensino médio, demanda uma maior presença dos meios de comunicação nas aulas como tema transversal no currículo. Comunicar, neste sentido, quer transformar-se em um fórum plural para a comunicação em educação, aberto a todos os profissionais dessa confluência de áreas que desejam trabalhar desinteressadamente para fomentar entre seus colegas um consumo mais plural e inovador da comunicação.

\section{A REVISTA COMUNICAR, UM FORO IBERO-AMERICANO DE INTERCÂMBIO PARA PESQUISADORES}

A revista científica ibero-americana de educação e comunicação, Comunicar $^{6}$ (ISSN: 1134-3478; e-ISSN: 1988-3293), surge em 1993, concomitantemente à consolidação do Grupo Comunicar como referência na Educação nos Meios de Comunicação ${ }^{7}$. Os cinco primeiros anos do Grupo Comunicar haviam sido fundamentais para a implantação das atividades de formação de professores e alunos, detectando-se a necessidade de estabelecer diretrizes para a formação e a conscientização. O seu surgimento dá-se paralelamente ao nascimento de Comunicação e Educação $o^{8}$, revista que compartilha dos mesmos princípios e objetivos. 
Nos últimos dezesseis anos, a revista Comunicar tem sido editada pontualmente a cada semestre, e vem se consolidado como revista científica de excelência nesta temática. Recentemente, a publicação foi incluída nos sistemas de indexação mais seletivos do mundo: o JCR (Journal Citation Reports), o SSCI (Social Sciences Citation Index), de Thomson Reuters (Philadelphia, USA) e Scopus (Europa), além de 50 índices, catálogos e repertórios internacionais, o que confere à revista cobertura nas melhores bibliotecas científicas do mundo e um alto nível de impacto de seus trabalhos. Além disso, Comunicar encontra-se integrada na Red Iberoamericana de Revistas de Comunicación e nas principais bases de dados latino-americanas: Latindex, Redalyc, Cedal, OEI, IRESIE, entre outras.

Comunicar tem entre seus objetivos dinamizar as relações entre os meios de comunicação e a educação, fomentando pesquisas e intercâmbio de ideias e experiências, e promovendo a necessária reflexão compartilhada entre jornalistas e docentes. A revista está presente, por rede de distribuição, em todas as comunidades da Espanha e em diversos países europeus e americanos; e ainda conta com centenas de assinaturas e permutas que a fazem chegar a todos os cantos do mundo.

Sua equipe é formada por um Comitê Científico e um Conselho Editorial composto de 51 especialistas, 28 dos quais são pesquisadores internacionais (de 16 países) e de 16 universidades espanholas e centros de pesquisa. Do total, 38 são doutores de centros de pesquisa de excelência.

Todos os trabalhos editados são submetidos a avaliações prévias por especialistas do Comitê e do Conselho, e também por pesquisadores independentes e de reconhecido prestígio na área. Mantém ainda uma estrita homogeneidade em sua linha editorial e na temática da publicação. Aceita originais em espanhol (primeiro idioma da revista), português, inglês ou francês.

Desde 1993, Comunicar realiza a cada semestre uma reunião com seus leitores e assinantes, ampliando temáticas e propostas. Hoje já é uma plataforma consolidada de expressão, aberta à participação e colaboração de todos os profissionais da educação e comunicação interessados nesta área transversal da Educação em Meios de Comunicação. Cada número enfoca um tema monográfico de pesquisa e contém ainda uma série de seções que incluem experiências, propostas, reflexões, estudos e resenhas bibliográficas. Os temas monográficos desenvolvidos têm abordado: Imprensa e níveis educativos (1), Meios de comunicação e áreas curriculares (2), Comunicação audiovisual no currículo (3), Compreender a comunicação audiovisual (4), Anúncios publicitários na sala de aula (5), A televisão na sala de aula (6), Por um consumo inteligente da comunicação (7), A Educação e os meios de comunicação (8), Educação em valores e meios de comunicação (9), A família e os meios de comunicação (10), O cinema na sala de aula (11), Estereótipos e meios de comunicação (12), Os meios de comunicação e a educação para a democracia (13), A comunicação humana. Desafios no 
comunicação \& educação • Ano XIV • Número 1 • jan/abr 2009

limiar do novo milênio (14), Educação para a solidariedade e a comunicação (15), Educação para a cooperação e o desenvolvimento com os meios de comunicação (16), As novas linguagens da comunicação (17), Descobrir os meios de comunicação (18), Comunicação e divulgação científica (19), Orientação e meios de comunicação (20), Tecnologias e comunicação (21), Educomunicação em um mundo global (22), Música e comunicação (23), Comunicação e currículo (24), Televisão de qualidade (25), Comunicação e saúde (26), Moda e comunicação (27), Educação e comunicação na Europa (28), O ensino do cinema (29), O público e a mídia na América (30), Educar o olhar. Aprender a ver televisão (31).

\section{REFERÊNCIAS BIBLIOGRÁFICAS}

AGUADED, J. I. C\&E, nuevas expectativas en América y Europa (C\&E, novas expectativas na América e na Europa). Comunicar, 30; 7-8. 2008.

BACCEGA, Maria Aparecida. Dez anos a serviço da construção do campo comunicação/ educação. Comunicação \& Educação. São Paulo: CCA-ECA-USP/Paulinas, ano X, n. 3, set./dez. 2005.

CEBRIÁN HERREROS, M. Información audiovisual. Concepto, técnica, expresión y aplicaciones (Informação audiovisual. Conceito, técnica, expressão e aplicações). Madrid: Síntesis, 1995.

OROZCO, G. Televisión y audiencias. Un enfoque cualitativo (Televisão e público. Um enfoque qualitativo). Madrid: La Torre, 1996.

SALOMON, G. Investing effort in television viewing (Investindo esforços na programação televisiva). In: MURRAY, J. y SALOMON, G. (Eds.). The future of children television ( $O$ futuro da televisão infantil). Nebraska: The Boys Town Center, 1984.

SANCHO, J. La tecnología, un modo de transformar el mundo cargado de ambivalencias (A tecnologia, um modo de transformar o mundo cheio de ambivalências), 1994. In: SAN MARTÍN, A. La escuela de las tecnologias (A escola das tecnologias). Valencia: Universidad de Valencia, 1995.

SOARES, Ismar. Quando o educador do ano é um educomunicador: o papel da USP na legitimação do conceito. Comunicação \& Educação. São Paulo: CCA-ECA-USP/ Paulinas, ano XIII, n. 3, set./dez. 2008. 